\title{
A case series study to explore the efficacy of plastic bands in closure of fasciotomy wounds and open fracture II, IIIA, IIIB: a dynamic wound closure
}

\begin{abstract}
Background: The care of compartment syndrome fasciotomy \& open fracture II, IIIA \& IIIB wounds begin with preoperative planning. The ultimate goal is to prevent infection \& facilitate healing. This study explores the use of plastic bands in closing fasciotomy wounds $\&$ open fracture.

Methods: The time to definite closure, complications, need for additional intervention, length of hospital stay and daily treatment cost in 10 patients were evaluated. Five patients with fasciotomy wounds \& five patients with open fractures treated with plastic bands for wound closure were evaluated.

Result: All fasciotomy wounds \& open fracture wounds in 10 patients closed successfully within 5 - 10 days. Only one patient developed minimal complication. A significant reduction in hospital stay, faster wound closure and lower daily treatment cost was observed.

Conclusion: This observational study demonstrated that the plastic band method used is cheaper, reliable and effective method in closure of fasciotomy wounds \& open fracture in comparison to similar techniques using the same device.
\end{abstract}

Keywords: Plastic bands; Fasciotomy wounds; Open fracture; Dynamic wound closure
Volume I Issue 4 - 2014

\author{
Abigail S Garcia, Leo Daniel D Caro,Carl \\ Ryan Taguba \\ East Avenue Medical Center, Diliman Quezon City, Philippines
}

Correspondence: Abigail S Garcia, Department of Orthopaedics East Avenue Medical Center, 6th floor, Diliman Quezon City, Philippines, Email asgarcia8I@gmail.com

Received: November 12, 2014 | Published: December I, 2014

\section{Introduction}

Complex wounds that involve skin and soft tissue defects that are unsuitable for primary closure by conventional suturing are common in the field of surgery. Post operative soft tissue management for compartment syndrome fasciotomy and Gustilo and Anderson Type II, IIIA and IIIB open fracture debridement wounds begins in the operating suite as the surgeon's plans for deferred, final wound closure. Various mechanical devices have been recently proposed for those patients that are being treated with delayed primary closure.

Immediate primary skin closure after fasciotomy is not advisable for two reasons:

a) Swelling of the extremity would force surgeon to apply suture material under tension, increasing the potential for dermal necrosis and wound breakdown and

b) Closure of the dermis can lead to increased compartment pressures, thus defeating the purpose of fasciotomy. ${ }^{1}$

Ultimately, delayed fasciotomy closure can be accomplished by primary suture methods, split thickness skin grafting, or secondary intention. Management of traumatic lower extremity wounds requires a comprehensive approach. No single device or technique can reliably lead to healing and prevention of infection in all situations. Goals of treatment must include a thorough debridement, preservation of vascularity to remaining tissue, facilitation of adequate drainage, and achievement of eventual coverage.

\section{Objectives}

The objectives is to explore the use of plastic bands (also known as zip-ties or cable ties) in closing fasciotomy wounds and Gustilo and
Anderson Type II, IIIA and IIIB Open fracture. And also to determine the time of wound closure, need for additional intervention, and complication. As well as to determine the length of hospital stay and Daily treatment cost.

\section{Patients and methods}

A total of ten patients, five with fasciotomies and five with open fractures, were evaluated and treated using plastic bands for wound closure (Table 1). The time to definite closure, complications, need for additional intervention, length of hospital stay and daily treatment cost were evaluated. The study was conducted according to the institutional guidelines for clinical studies and all patients received thorough explanation of the study and signed informed consent.

\section{Details of the procedure}

Immediately following fasciotomy and/or debridement and irrigation while the patient still in anesthesia, the plastic bands (Figure 1A), sterilized using ethylene oxide gas, ${ }^{1,2}$ were first threaded into a piece of sterile size 10 nasogastric tube (Figure 1B) which protects the skin from the sharp edge of the band cutting through; then the threaded band is inserted approximately $2-3 \mathrm{~cm}$ apart through a full thickness small stab wound $1 \mathrm{~cm}$ from the wound edge. ${ }^{2}$ The number of bands will depend on the length of the wound. All bands will be locked without exerting undue tension on the skin margins. The bands will be tightened every 48 hrs, gradually by $2-3$ clicks (approximately $2-3 \mathrm{~mm}$ ) without overstretching the skin, until the wound edges approximated and finally stitched under local.

\section{Results}

Wound closure was achieved in nine patients (Table 1) within 
5-10 days with good result. Complications were noted in one patient who developed wound infection and skin necrosis which was treated with antibiotics and underwent debridement and irrigation with split thickness skin graft of the leg. Wound parameters assessed in the patients are presented in (Table 2).

Table I Details of patients

\begin{tabular}{|c|c|c|c|c|c|c|}
\hline Case & Age/Sex & Type of Injury & $\begin{array}{l}\text { Location of } \\
\text { Wound }\end{array}$ & $\begin{array}{l}\text { Wound Size } \\
\text { (length } x \text { width) }\end{array}$ & $\begin{array}{l}\text { Time Taken to Close } \\
\text { Wounds (days) }\end{array}$ & Complications \\
\hline I & $7 / M$ & $\begin{array}{l}\text { Acute Compartment } \\
\text { Syndrome }\end{array}$ & $L$ foot & $21 \mathrm{~cm}^{2}$ & 4 days & Nil \\
\hline 2 & I9/M & $\begin{array}{l}\text { Acute Compartment } \\
\text { Syndrome }\end{array}$ & $L$ foot & $18 \mathrm{~cm}^{2}$ & 6 days & Nil \\
\hline 3 & I9/M & $\begin{array}{l}\text { Acute Compartment } \\
\text { Syndrome }\end{array}$ & $\mathrm{R}$ leg & $68 \mathrm{~cm}^{2}$ & 20 days & Nil \\
\hline 4 & I9/M & $\begin{array}{l}\text { Acute Compartment } \\
\text { Syndrome }\end{array}$ & $R$ foot & $10 \mathrm{~cm}^{2}$ & 10 days & Nil \\
\hline 5 & $28 / M$ & $\begin{array}{l}\text { Acute Compartment } \\
\text { Syndrome }\end{array}$ & R leg & $62.5 \mathrm{~cm}^{2}$ & 16 days & Nil \\
\hline 6 & $20 / M$ & Fracture, Open IIIB & L leg & $112 \mathrm{~cm}^{2}$ & 16 days & $\begin{array}{l}(+) \text { infection (Skin } \\
\text { necrosis) }\end{array}$ \\
\hline 7 & I9/M & Fracture, Open IIIA & $\mathrm{R}$ leg & $52 \mathrm{~cm}^{2}$ & 13 days & Nil \\
\hline 8 & $37 / M$ & Fracture, Open IIIA & R leg & $33 \mathrm{~cm}^{2}$ & 8 days & $\mathrm{Nil}$ \\
\hline 9 & $14 / M$ & Fracture, Open II & R leg & $8 \mathrm{~cm}^{2}$ & 5 days & Nil \\
\hline 10 & $24 / M$ & Fracture, Open IIIA & L leg & $60 \mathrm{~cm}^{2}$ & 10 days & Nil \\
\hline
\end{tabular}

Table 2 Wound parameters

\begin{tabular}{ll}
\hline Parameter & Plastic Bands $(\mathbf{N}=10)$ \\
\hline Mean Closure Time (days) & I0.8 days \\
Complication $(\mathrm{n})$ & $\mathrm{I}$ \\
Additional Intervention & $\mathrm{I}$ \\
Length of Hospital Stay & 38.5 days \\
Daily Treatment Cost & P50 \\
\hline
\end{tabular}

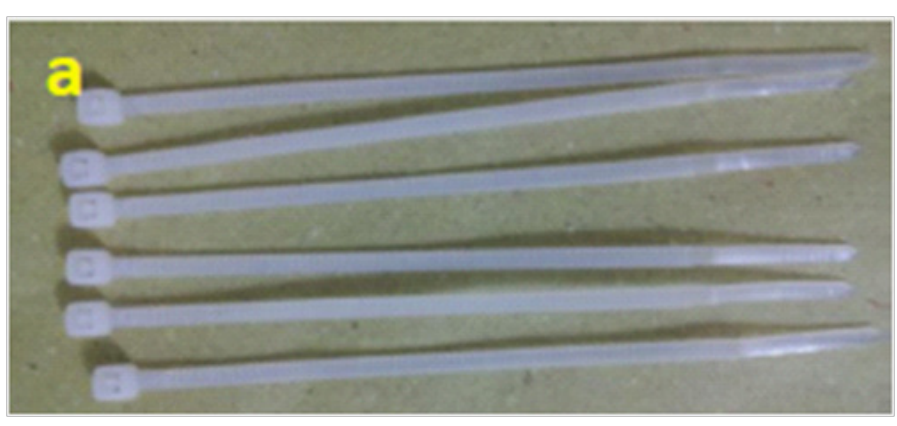

Figure Ia Plastic bands.

\section{Discussion}

The goals of soft tissue wound care associated with open fractures and compartment syndromes are to prevent infection, expedite healing and restore optimal function.1 Closure of wounds with skin and soft tissue deficits poses a challenge to surgeons of all specialties. The surgeon should have the knowledge of wound grading and repair, debridement, dressings, soft tissue transfers, antibiotics and strategies for handling open fractures in the presence of compartment syndrome.

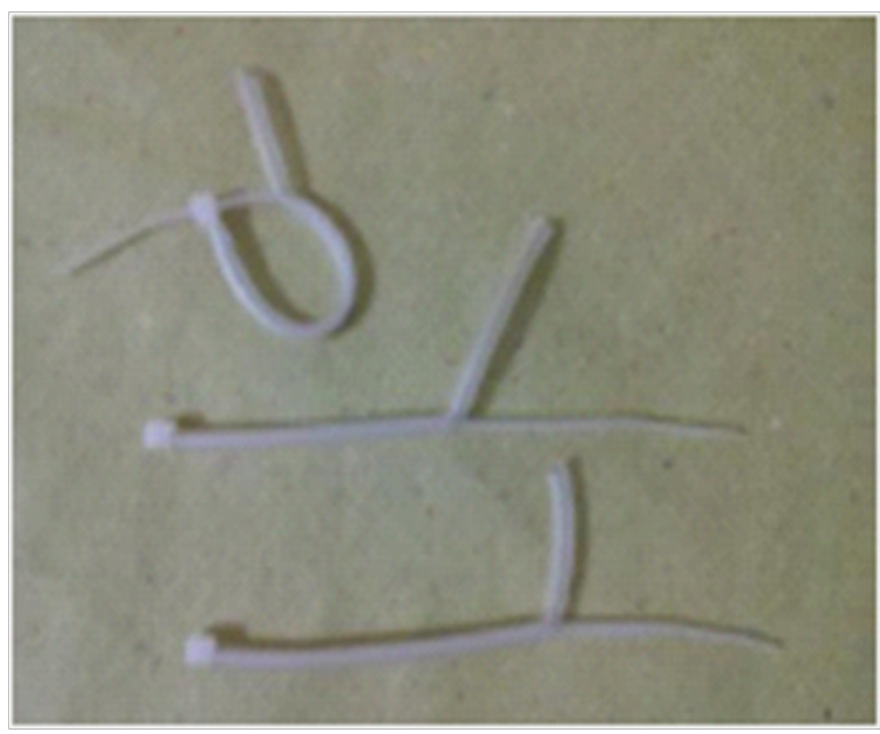

Figure I b Plastic bands within the tube.

Commonly employed technique for post operative management of fasciotomy wounds often include serial dressing changes, either on the floor or in the operating room. The goal of these dressing changes is to keep the wound bed clean while swelling resolves before definitive closure of wound or coverage with a split thickness skin graft.3-5 A major disadvantage of this type of wound management is that it necessarily exposes the wound to the unsterile environment of the hospital ward. The risk of secondary contamination of the wound is therefore high. Management of traumatic extremity wounds requires a thorough debridement. Wounds must be thoroughly explored, 
and the treating surgeon must thoroughly demonstrate that all cross contamination from an open wound has been adequately debrided. Many authors have advocated early closure or coverage of open traumatic wounds in the extremities, particularly in the context of open fractures, however no available evidence suggests that delay in coverage is advantageous. Many techniques have been described for safe closure of the wounds and controversy exists as to the optimal method. Healing by secondary intention used to be a commonly employed technique that tends to be less popular nowadays, due to the increased risk of infection, lengthy hospitalization, increased requirements of frequent dressing changes, delay in rehabilitation, and significant scarring and poor aesthetic outcome. ${ }^{6}$ The method we describe in this report was first described by Suliman and Aizaz ${ }^{2}$ for forearm fasciotomy using plastic bands.

There is much debate regarding the best method to achieve primary closure of such wounds. Many of these closure techniques take advantage of the distinctive properties of the skin. Skin has unique biomechanical and physiologic properties such as skin tension, inherent extensibility, and mechanical and biologic creep. ${ }^{5,7}$ Skin tension is a function of the elastic fiber network and is visible by the contraction of wound margins when incisions are made. Skin extensibility is the response of skin to mechanical forces. The collagen fibers straighten longitudinally in the direction of the stretching force when a continuous load is applied until the fibers are parallel and resist further extension..$^{5,89}$ These inherent properties of skin contribute to the success of delayed skin closure.

In our study, we found that the plastic bands offered some advantages over other methods and devices for wound closure. Surgical preparation for wound closure included minimal wound dissection, with no skin undermining, allowing maximal preservation of the neurovascular supply to the skin. This in effect shortened the operating time and hospital stay, consequently reducing the treatment cost. Another advantage found was the versatility and flexibility of the bands in accommodating different sizes and shapes in different anatomical body areas. Its application was technically simple, and permitted controlled approximation of the wound edges. Patient compliance with the device was good despite some degree of pain and discomfort during the process which was relieved with oral analgesics (Figure 2 \& 3).

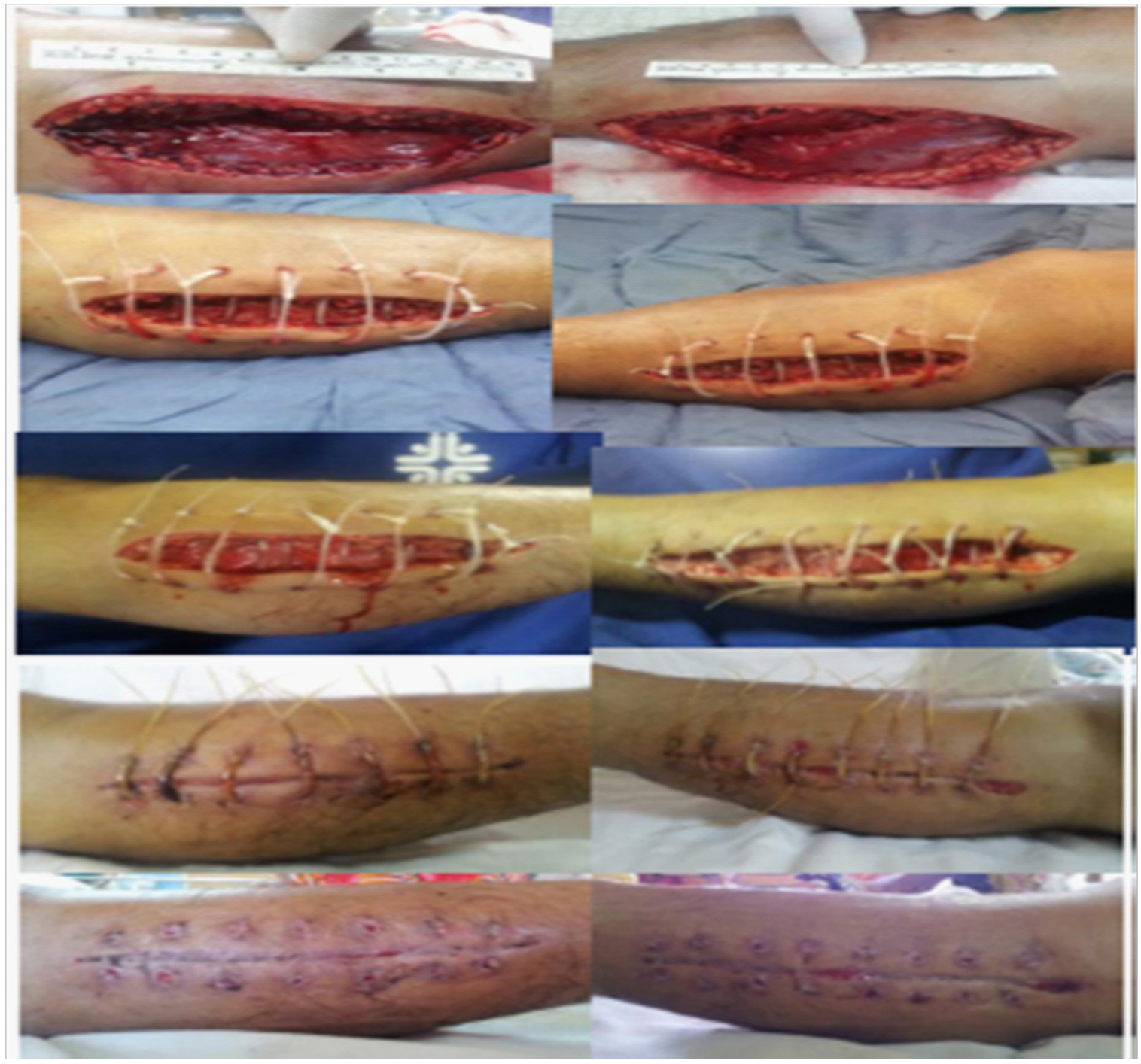

Figure $2 \mathrm{~A}$ case of 34 year old male, involved in motorcycle accident, and occurred acute compartment syndrome, emergency fasciotomy was done, and applied plastic bands.

Citation: Garcia AS, Caro LDD, Taguba CR.A case series study to explore the efficacy of plastic bands in closure of fasciotomy wounds and open fracture II, IIIA, IIIB: a dynamic wound closure. MOJ Orthop Rheumatol. 20I4;I (4):97-I00. DOI: I0.15406/mojor.2014.01.0002I 


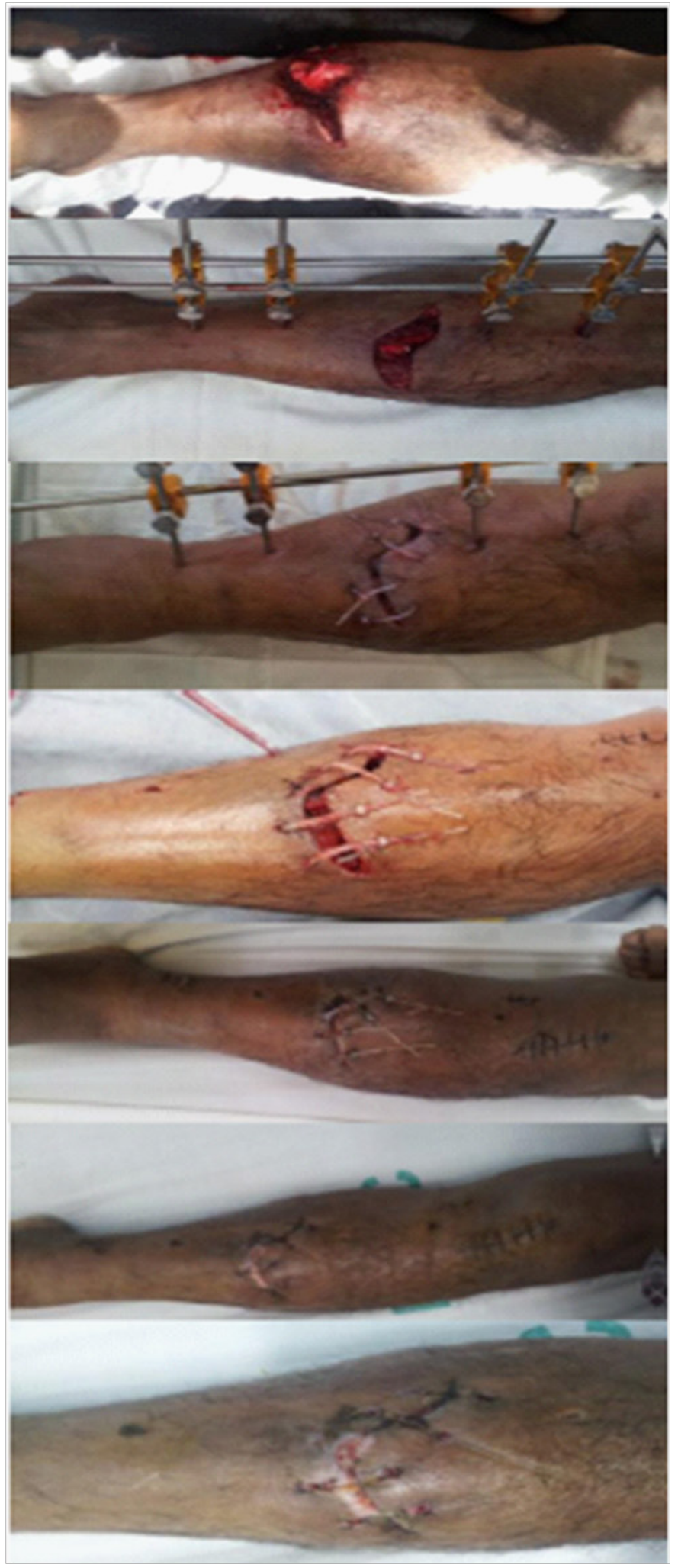

Figure $3 \mathrm{~A}$ case of 37 year old, male, involved in a vehicular crash sustaining Fracture, open IIIA, complete, displaced, transverse, middle $3^{\text {rd }}$, tibia, left, and underwent emergency debridement and irrigation of left leg with application of external fixation and applied plastic bands. On $3^{\text {rd }}$ day post op, patient underwent conversion to closed reduction internal fixation intramedullary nailing of tibia, maintained with plastic bands.

\section{Conclusion}

Using this technique significantly improves the ability to close wounds primarily and decreases treatment time and overall recovery time. It can be concluded that closure of fasciotomy wounds and for Gustilo Type II and III fracture wounds can be use as a cheap, effective alternative method for wound closure.

\section{References}

1. Abene JJ, Esterhai JL. Soft tissue management of Compartment Syndrome Fasciotomy and Gustilo and Anderson Type Iiib open fracture wounds. Techniques in Orthopaedics. 1997;12(2):127-132.

2. Suliman MT, Aizaz S. Closing fasciotomy wounds using plastic bands: An alternative simple and cheap method. Ann Vasc Surg. 2008;22(5):697700 .

3. Zannis J, Angobaldo J, Marks M, et al. Comparison of Fasciotomy wound closure using traditional dressing changes and the vacuum-assited closure device. Ann Plast Surg. 2009;62(4):407-409.

4. Barnea Y, Gur E, Amir A, et al. Our experience with wise bands: a new skin and soft tissue stretch device. Plast Reconstr Surg. 2004;113(3):862869.

5. Caruso D, King TJ, Tsujimura RB, et al. Primary closure of fasciotomy incisions with a skin stretching device in patients with burn and trauma. $J$ Burn Care Rehabil. 1997;18(2):125-132.

6. Kakagia D, Karadimas EJ, Drosos G, et al. Wound closure of leg fasciotomy: Comparison of vacuum-assisted closure versus shoelace technique. Injury. 2012;45(5):890-893.

7. Zorilla P, Marin A, Gomez LA, et al. Shoelace technique for gradual closure of fasciotomy wounds. J Trauma. 2005;59(6):1515-1517.

8. Asgari MM, Spinelli HM. The vessel loop shoelace technique for closure of fasciotomy wounds. Annals of Plastic Surgery. 2000;44(2):225-229.

9. Naranja RJ, Chan PSH, Esterhai JL, et al. Analysis of hospital days after wound closure for fasciotomy: delayed primary closure versus split thickness skin graft. Techniques in Orthopedics. 1997;12(2):90-91. 